\title{
Comparison of the Effectiveness of Intra-Articular Injections of Hyaluronic Acid and Corticosteroid in the Treatment of Patients with Knee Osteoarthritis Symptomse
}

\author{
Majid Abedi ${ }^{1}$, Pouyan Kamkar ${ }^{2}$, Mahdi Afshari ${ }^{3}$ and Masoud Mirkazemi ${ }^{4^{*}}$ \\ ${ }^{1}$ Bone and Joint Reconstruction Research Center, Shafa Orthopedic Hospital, Iran University of Medical Sciences, Tehran, IR Iran. \\ ${ }^{2}$ Student Research Committee, Zabol University of Medical Sciences, Sistan Balochestan, Iran. \\ ${ }^{3}$ Department of Statistics, Faculty of Medicine, Zabol University of Medical Sciences, Sistan Balochestan, I. R, Iran. \\ ${ }^{4}$ Bone and Joint Reconstruction Research Center, Shafa Orthopedic Hospital, Iran University of Medical Sciences, Tehran, IR Iran.
}

Submission: April 29, 2017; Published: May 12,2017

*Corresponding author: Masoud Mirkazemi, Fellowship of Orthopedic Oncology, Bone and Joint Reconstruction Research Center, Shafa Orthopedic Hospital, Iran University of Medical Sciences, Tehran, IR Iran, Tel: +985136004359; Email: masoud.dr2003@gmail.com

\begin{abstract}
Background: Osteoarthritis is one of the most common degenerative disorders of cartilage in old age the treatment and prevention of which poses a tremendous challenge. The aim of this study was to compare the effects of hyaluronic acid and corticosteroids in the treatment of knee osteoarthritis.

Materials and Methods: In this clinical trial, 34patients with knee osteoarthritis were enrolled. Patients were randomly divided into two groups. In this study hyaluronic acid was administrated at a dose of $20 \mathrm{mg}$ per $2 \mathrm{ml}$ ( 3 infusions every 2 weeks) and triamcinolone acetate was administrated at a dose of $40 \mathrm{mg}$ per $1 \mathrm{cc}$ and $1 \mathrm{cc}$ of lidocaine (1injection). Pain, joint stiffness, movement restriction and grad of osteoarthritis were compared in the two groups.
\end{abstract}

Results: The results showed that hyaluronic acid relieved movement restriction (41.58 to 28.35) (PV $=0.001)$ and corticosteroids reduced pain (14.52 to 12.52) (PV = 0/011) in patients

Conclusion: The results suggested the effect of hyaluronic acid on reducing restriction of movement and corticosteroids on pain relief in patients.

Keywords: Knee osteoarthritis; Hyaluronic acid; Corticosteroids

\section{Introduction}

Osteoarthritis $(\mathrm{OA})$ is a common degenerative disorder of articular cartilage accompanied by hypertrophic changes of the bone. The risk factors include genetics, female gender, trauma, age and obesity. It is associated with progressive degeneration of cartilage and formation of new bone at the joint $[1,2]$. The most common symptoms of osteoarthritis are progressive pain, which is intermittent and mild at first, but grows more chronic and debilitating over time. The pain is usually mitigated by rest and deteriorated by movement in patients [3]. Joints that are more likely to be affected are hands, knees, hips and spine. Osteoarthritis is often asymmetric [1]. The common medicines that are administered to patients with osteoarthritis are acetaminophen, non steroidal anti-inflammatory drugs, tramadol, narcotic analgesics and corticosteroids. Other treatment alternatives such as glucosamine sulfate, chondroitin and methyl sulfonylurea methane are also used for this disease [4]. Current treatments such as the use of steroids and non steroidal anti-inflammatory drugs are not satisfactory due to their significant side effects and poor therapeutic results. For this reason, attempts have been made to find novel methods [5].

A combination of glucosamine supplements and chondroitin can be useful in moderate to severe osteoarthritis. Intra-articular corticosteroid injection is inexpensive and leads to short-term improvement (4-8 weeks) in knee osteoarthritis resonances. 
Conversely, injections of hyaluronic acid is more expensive, but it helps achieve long-term improvement of symptoms. Total replacement of hip, knee or shoulder joint is recommended for patients with chronic pain and joint dysfunction, despite maximum medical therapy [1].

Hyaluronic acid provides softening, adhesive and elastic properties for synovial fluid, which improves joint function. In osteoarthritis, the concentration and molecular weight of hyaluronic acid is reduced by $33-50 \%$ due to elevated levels of pro-inflammatory cytokines, free radicals and proteases. Given the effect of hyaluronic acid on joint function due to its lubricant properties and intra-articular reduction of this substance in patients with OA, the articular injection of hyaluronic acid has been proposed as a new treatment of osteoarthritis [3]. Peyron was one of the first to apply this procedure for the treatment of rheumatoid synovitis to more than 336 patients in 1993 [2].

Although the injection of hyaluronic acid and corticosteroid is widely used to alleviate the symptoms of knee osteoarthritis, few studies have compared the effectiveness of these two procedures. Each year, more than 200,000 reconstructive surgeries are performed on knees in the United States but only a fraction of patients are satisfied with these surgical procedures and most prefer drug therapies [6]. The aim of the study was to compare the effects of intra-articular injections of hyaluronic acids and corticosteroids in the treatment of symptoms of knee osteoarthritis in an attempt to raise awareness about the treatment of osteoarthritis.

\section{Method}

This is an interventional study. Participants included all patients referring to a general hospital in Zabul, Iran, in the summer of 2015. According to Jones et al. [7], to obtain a score difference of nearly 10 points in patients' pain in the two treatment groups by considering a type-I error of 0.05 , power of 0.90 and $20 \%$ subject mortality rate, a sample size of $n=17$ was selected for both treatment groups (total of 34 subjects).

Inclusion criteria were patients with a definitive diagnosis of knee osteoarthritis based on ACR criteria (American College of Rheumatology) referred to the said hospital, who were willing to participate in the study and were older than 40 years. Exclusion criteria were suffering from arthritis and other inflammatory diseases, using analgesics and anti-inflammatory drugs as well as drugs administered in the trial one month prior to the study, a history of knee surgery and unwillingness to participate in the study.

Prior to the study, all patients received a questionnaire in which they recorded the severity of pain and joint stiffness as well as impaired daily activities. Knee osteoarthritis was diagnosed based on criteria of American College of Rheumatology (ACR) for patients for at least six months. Patients with a recent history of knee surgery and all types of secondary osteoarthritis were excluded. Patients, who stopped taking medicines for any reason such as drug side effects or arbitrary decision, were also excluded. At the baseline, all patients had a knee X-rays based on which the severity of osteoarthritis was determined. To do so, Kellgren-Lawrenc classification of radiographic changes was adopted [8] (Table 1).

Table 1: Kellgren-Lawrence classification of radiological changes.

\begin{tabular}{|c|c|}
\hline Grade & Description \\
\hline 1 & Joint space narrowing (JSN) \\
\hline 2 & Grade 1 severity \\
\hline 3 & $\begin{array}{c}\text { Grade } 1 \text { and } 2 \text { loss of joint space } \\
\text { (formation of osteophytes) }\end{array}$ \\
\hline 4 & Grade 1, 2 and 3 bone cysts \\
\hline
\end{tabular}

The purpose of this classification was to first determine the severity of osteoarthritis in patients and then assess the effectiveness of intra-articular corticosteroid injections and hyaluronic acid in treating symptoms of knee osteoarthritis based on the Kellgren-Lawrence classification of radiological changes. In the beginning of the project, patients were randomly divided into two groups based on the time of admission to the orthopedic clinic, with each group receiving a particular treatment. In this trial, hyaluronic acid at a dose of $20 \mathrm{mg}$ per $2 \mathrm{ml}$ ( 3 injections every 2 weeks) and triamcinolone acetate at a dose of $40 \mathrm{mg}$ in $1 \mathrm{ml}$ along with $1 \mathrm{cc}$ of lidocaine ( 1 injection) were used. A minimum intake of $80 \%$ of medication was essential for patients and those who failed to meet this criterion or took high doses of painkiller during the study were excluded.

During the intervention, the patients were allowed to take acetaminophen (PRN) to ease their pain, if necessary, but other drugs such as NSAIDs or tramadol an analgesic were prohibited. Acetaminophen was used only in urgent cases and the number of pills taken by each patient was recorded. The maximum permitted dosage of acetaminophen was $25.3 \mathrm{mg}$ per week, i.e. 10 acetaminophen tablets, and patients who exceeded this limit were excluded. Moreover, patients who complained of severe pain were examined again and if a new treatment that could interfere with the results of the study was required, they were excluded from the study.

The initial severity of pain was measured using the WOMAC index which consisted of 24 items rated on a scale of 0 to 4 (the numeral value was in the range of 0 to 96). Six month later, patients were asked to complete the same questionnaire and the results before and after injection were compared. Joint stiffness and limitation of movement were also evaluated in a fashion similar to the initial severity of pain. During the trial, patients were continuously in contact with researchers and instructions regarding the factors affecting the recovery of patients, such as weight loss, proper diet, non-use of prohibited drugs, avoiding traditional Iranian toilets and stairs, wearing appropriate 


\section{Orthopedics and Rheumatology Open Access Journal}

shoes, etc. were presented. In addition, patient's questions were answered throughout the project.

\section{Statistical Analysis}

All patient data including demographic factors and paraclinical symptom were recorded in the self-administered checklist and entered in SPSS00 software. The statistical analysis was presented in two descriptive and analytical parts. In the descriptive part, mean and standard deviation of pain severity, joint stiffness and restricted movement were presented as primary variables in the different groups and all demographic and clinical parameters were also reported based on descriptive criteria. In the analytical part, based on statistical assumptions, appropriate parametric and non-parametric tests were used. Qualitative and quantitative data analysis was performed by Chi-square test and independent t-test respectively. Where basic assumptions such as normality of data were not established, Mann-Whitney was used. All tests were examined at an error level of 5\% (Figure 1).

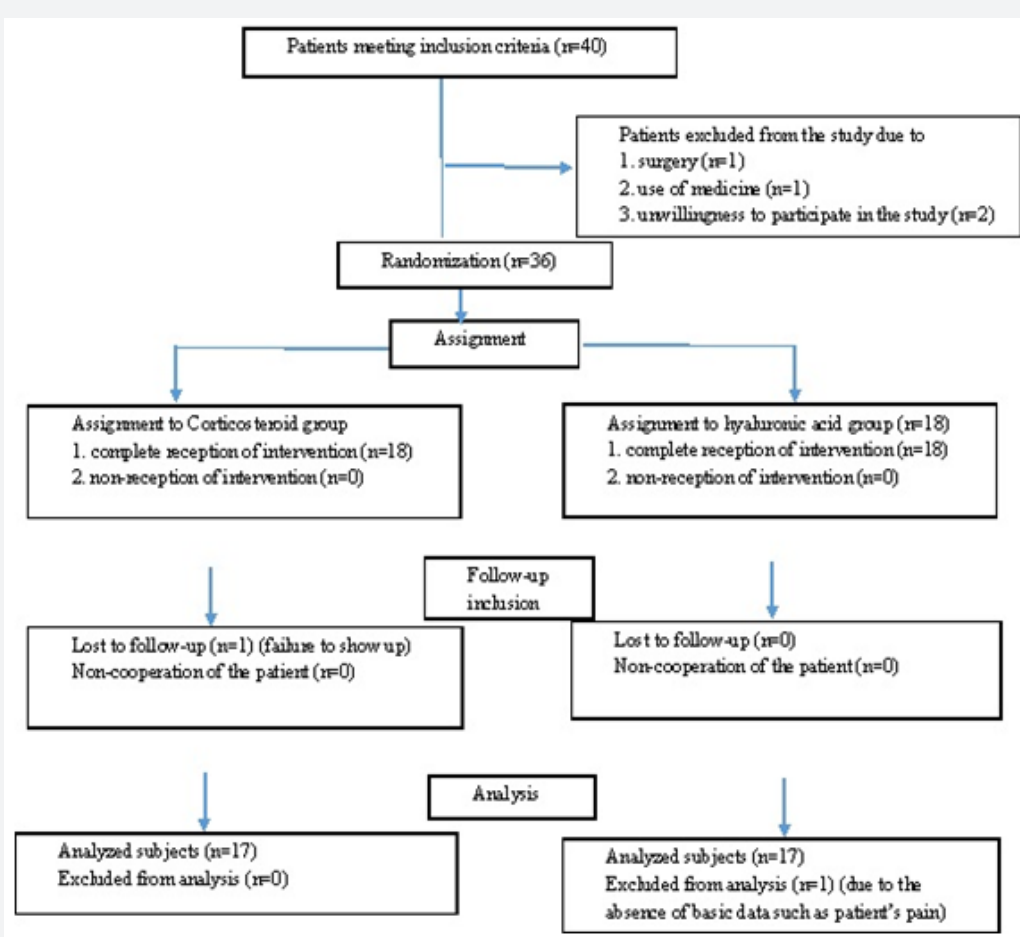

Figure 1: Study flowchart (CONSORT forma).

\section{Results}

This study was performed on 34 patients who were equally divided into hyaluronic acid (50\%) and corticosteroid (50\%) groups. The results of our study demonstrated that of 34 patients under study, 11 (32.4\%) were male and 23 (67.6\%) were female. The mean age of patients was $57.97 \pm 7.09$ years, and patients were in the age range of 45 to 70.

Table 2: Prevalence and demographic variables in two groups of patients.

\begin{tabular}{|c|c|c|c|c|}
\hline \multicolumn{2}{|c|}{$\begin{array}{c}\text { Variable } \\
\text { Group }\end{array}$} & $\begin{array}{c}\text { Hyaluronic } \\
\text { acid }\end{array}$ & Corticosteroids & P-value \\
\hline \multirow{2}{*}{ Age } & & $5.74 \pm 57.29$ & $8.35 \pm 58.64$ & 0.5 \\
\hline \multirow{2}{*}{ Gender } & Male & $29.4 \%) 5)$ & $6(35.3 \%)$ & \multirow{2}{*}{0.7} \\
\cline { 2 - 5 } & Female & $70.6 \%) 12)$ & $(64.7 \%) 11$ & \multirow{2}{*}{0.2} \\
\hline \multirow{2}{*}{ Pain } & Pretreatment & $14.11 \pm 3.68$ & $14.52 \pm 2.85$ & \\
\cline { 2 - 5 } & Post-treatment & $13.64 \pm 2.78$ & $12.52 \pm 2.23$ & \\
\hline
\end{tabular}

\begin{tabular}{|c|c|c|c|c|}
\hline \multirow{2}{*}{$\begin{array}{c}\text { Join } \\
\text { stiffness }\end{array}$} & Pretreatment & $4.64 \pm 1.22$ & $4.88 \pm 1.49$ & 0.6 \\
\cline { 2 - 5 } & Post-treatment & $4.41 \pm 1.46$ & $4.5882 \pm 1.9$ & 0.7 \\
\hline $\begin{array}{l}\text { Movement } \\
\text { restriction }\end{array}$ & Pretreatment & $41.58 \pm 15.84$ & $38.41 \pm 12.57$ & 0.5 \\
\cline { 2 - 5 } & Post-treatment & $28.35 \pm 9.36$ & $34.52 \pm 8.92$ & 0.051 \\
\hline
\end{tabular}

The frequency of $\mathrm{OA}$ in both groups was similar $(\mathrm{P}=0.9)$. Further, the severity of pain before $(\mathrm{P}=0.7)$ and after treatment $(\mathrm{P}$ $=0.2$ ), joint stiffness before $(\mathrm{P}=0.6)$ and after treatment $(\mathrm{P}=0.7)$ and movement restriction before $(\mathrm{P}=0.5)$ and after treatment $(\mathrm{P}=0.051)$ were also identical in the two groups of hyaluronic acid and corticosteroids. Also, even despite the differentiation of three main variables based on the severity of $\mathrm{OA}$, changes were not significant $(\mathrm{P}>0.05)$ (Table 2$)$.

There was a significant decline in average movement restriction in patients treated with hyaluronic acid after treatment (from 41.58 in pre-treatment to 28.35 in posttreatment), which was statistically significant $(\mathrm{P}=0.001)$. With regard to the variables of pain and joint stiffness, no significant changes were observed. Also, there was a significant decline 
in average movement restriction of patients treated with corticosteroids after treatment (from 14.52 in pre-treatment to 12.52 in post-treatment), which was statistically significant

Table 3: Mean difference of variables under study in hyaluronic acid and corticosteroids groups before and after treatment.

\begin{tabular}{|c|c|c|c|c|c|c|c|c|}
\hline Group & Variable & Time & Mean & SD & $\begin{array}{c}\text { Mean } \\
\text { difference }\end{array}$ & $\begin{array}{l}\text { Standard } \\
\text { deviation } \\
\text { difference }\end{array}$ & $\mathbf{T}$ & p-value \\
\hline \multirow{6}{*}{ hyaluronic acid } & \multirow[b]{2}{*}{ Pain } & Pretreatment & 14.11 & 3.68 & \multirow[b]{2}{*}{0.47} & \multirow[b]{2}{*}{4.97} & \multirow[b]{2}{*}{0.390} & \multirow[b]{2}{*}{0.7} \\
\hline & & $\begin{array}{c}\text { Post- } \\
\text { treatment }\end{array}$ & 1364 & 2.78 & & & & \\
\hline & \multirow[b]{2}{*}{ Join stiffness } & Pretreatment & 4.64 & 1.22 & \multirow[b]{2}{*}{0.23} & \multirow[b]{2}{*}{1.92} & \multirow[b]{2}{*}{0.505} & \multirow[b]{2}{*}{0.6} \\
\hline & & $\begin{array}{c}\text { Post- } \\
\text { treatment }\end{array}$ & 4.41 & 1.46 & & & & \\
\hline & \multirow{2}{*}{$\begin{array}{l}\text { Movement } \\
\text { restriction }\end{array}$} & Pretreatment & 41.58 & 15.84 & \multirow[b]{2}{*}{13.23} & \multirow[b]{2}{*}{13.45} & \multirow[b]{2}{*}{4.055} & \multirow[b]{2}{*}{0.001} \\
\hline & & $\begin{array}{c}\text { Post- } \\
\text { treatment }\end{array}$ & 28.35 & 9.36 & & & & \\
\hline \multirow{6}{*}{ corticosteroids } & \multirow[b]{2}{*}{ Pain } & Pretreatment & 14.52 & 2.85 & \multirow[b]{2}{*}{2} & \multirow[b]{2}{*}{2.85} & \multirow[b]{2}{*}{2.893} & \multirow[b]{2}{*}{0.011} \\
\hline & & $\begin{array}{c}\text { Post- } \\
\text { treatment }\end{array}$ & 12.52 & 223 & & & & \\
\hline & \multirow[b]{2}{*}{ Join stiffness } & Pretreatment & 4.88 & 1.49 & \multirow[b]{2}{*}{0.29} & \multirow[b]{2}{*}{2.51} & \multirow[b]{2}{*}{0.481} & \multirow[b]{2}{*}{0.6} \\
\hline & & $\begin{array}{c}\text { Post- } \\
\text { treatment }\end{array}$ & 4.58 & 1.9 & & & & \\
\hline & \multirow{2}{*}{$\begin{array}{l}\text { Movement } \\
\text { restriction }\end{array}$} & Pretreatment & 38.41 & 12.57 & \multirow[b]{2}{*}{3.88} & \multirow[b]{2}{*}{18.81} & \multirow[b]{2}{*}{0.851} & \multirow[b]{2}{*}{0.4} \\
\hline & & $\begin{array}{c}\text { Post- } \\
\text { treatment }\end{array}$ & 34.52 & 8.92 & & & & \\
\hline
\end{tabular}

\section{Discussion}

The present study was intended to compare the effects of intra-articular injection of hyaluronic acid and corticosteroids in the treatment of knee osteoarthritis symptoms in patients referring to Imam Ali Hospital in Zabulm Iran in 2015. The results of suggested that in patients treated with hyaluronic acid, movement restriction had improved significantly but in patients receiving corticosteroids, a deterioration of pain was observed.

In 2011, Zahedi et al., randomly divided dogs into two groups (hyaluronic acid) and control (normal saline). Osteonecrosis was observed in the sample $(n=5)$ and control $(n=2)$ groups, although they were not statistically significant. However, the prevalence of osteonecrosis was dropped by 2.2 times after the injection of hyaluronic acid. It was concluded that the injection of hyaluronic acid was effective in preventing osteonecrosis after femoral neck osteotomy [9]. The results of this study also revealed that administration of hyaluronic acid significantly improved movement restriction in patients.

A study by Yeganeh et al. in 2007 showed that severity of pain 6 and 24 weeks after treatment in resting patients was 4.9 and 4.7 in hyaluronic acid injection group, 1.5 and 1.6 in corticosteroid injection group and 6.6 and 6.9 in the group taking anti-inflammatory drugs respectively. In ambulatory patients, severity of pain was 5.2 and 4.9 in hyaluronic acid injection group, 3.2 and 3.3 in corticosteroid injection group and 6.8 and 7.6 in the groups taking anti-inflammatory drugs, respectively.
$(\mathrm{P}=0.011)$. Similarly, changes in join stiffness and movement restrictions were not significant as well (Table 3).

28 patients $(70 \%)$ in the hyaluronic acid injection group and 16 patients $(100 \%)$ in the corticosteroid injection group were satisfied with the treatment results. It was concluded that analgesic effects and patients' improvement was more significant in patients injected with methyl prednisolone. However, given that this drug had been reported to cause joint damage and the injection of hyaluronic acid had analgesic effect matching that of methyl prednisolone without any harmful effects, it was acid was considered as an effective drug [10]. The results of said study are consistent with our findings in which pain in the group receiving corticosteroid was less severe than hyaluronic acid group.

In a study by Razavi et al. in 2012, there was no significant difference between the two groups in scores of knee pain and function. All scores of Osteoarthritis Outcome Score (KOO) questionnaire showed significant improvement after treatment. Score change at the baseline and post-treatment were not significantly different between the two groups. It was concluded that intra-articular injections of dextrose prolotherapy 25\% was as effective as hyaluronic acid (Synocrom Forte 1\%) in the treatment of knee osteoarthritis [11] The results of said study are not in agreement with this paper, as in our study hyaluronic acid did not have any significant effect on pain alleviation and it only enhanced movement restriction. This disparity could be explained in terms of study populations and their demographic features as well as different drug dosage. administered in the study. In the treatment process, hyaluronic 
Leopold et al. in their study on the effectiveness of intraarticular injection of corticosteroids and hyaluronic acid in treatment of knee osteoarthritis in 2007 did not report any disparity between the two drugs in terms of pain relief [6]. Their findings are inconsistent with ours because in this study, a significant pain alleviation was observed in the group injected by corticosteroid. Such discrepancy in results may be due to different populations and doses of the drug.

In 2009, Bannuru et al. studied the effectiveness of corticosteroid injections and hyaluronic acid in reducing the symptoms of knee osteoarthritis, concluding that corticosteroid was more effective in reducing symptoms in short-term ( 2 weeks) whereas in long terms ( 8 weeks) hyaluronic acid was proved to be more effective than corticosteroids in relieving symptoms [12]. In our study, such temporal difference was not taken into account, but it was found that corticosteroid alleviated pain and by hyaluronic acid improved movement restriction [13].

In a study by Creamer et al. on the effect of hyaluronic acid and placebo on increasing the generation of proteoglycans and reducing symptoms of osteoarthritis in 1994, it was concluded that hyaluronic acid had no effect on increasing the generation of proteoglycan but it mitigated symptoms in the long term [13]. In this study, we also found that hyaluronic acid could improve the patient's mobility.

\section{Conclusion}

The results suggested that hyaluronic acid relieved movement restriction and corticosteroids mitigated pain in patients without any change in joint stiffness in both groups. These results were true about all grades of osteoarthritis. Therefore, in patients with osteoarthritis, a combination of these two drugs can be administered to alleviate pain and reduce movement restrictions.

\section{Acknowledgment}

This paper was based on a doctoral dissertation and supported by the Research Department of Zabol University of Medical Sciences. We hereby acknowledge the efforts of all people who helped us throughout this study.

\section{References}

1. Sinusas K (2012) Osteoarthritis: diagnosis and treatment. AFP 85(1): 49-56.
2. Meftah M, Moridpour D, Meftah A (2003) Comparison of hyaline therapy results with NSAID therapy in patients with knee osteoarthritis. Pazhouhande 7(4): 331-335.

3. Rashi Tripathy D, Kumar Talele M, Kumar A, Uppal H, Kumar D (2015) Visco supplementation with Hyaluronic acid an Adjuvant to Diacerein in improving Pain, Stiffness and Physical function in Primary Osteoarthritic Knees: a 1 year follow-up observation study. Al Ameen J Med Sci 8(1): 35-44.

4. Rajai A, Alirezaee AH, Valaei N (2004) Comparison of the effect of glucosamine sulfate and glucosaminemethyl sulfonyl methane in treating symptoms of osteoarthritis. Pazouhandeh 14 (5): 283-287.

5. Esmailijah A, Abbasian MH, Hosseinzadeh HR, Jazayeri M, HasasYeganeh M, et al. () Comparison of the effect of the analgesic effect of intra-articular injection of hyaluronic acid, methyl prednisolone and orally-administered naproxen in women with knee osteoarthritis. Iranian Journal of orthopedic and joint surgery 6(22): 74-80.

6. Leopold S, B Redd, J Warme, A Wehrle P, D Pettis P, et al. (2003) Corticosteroid Compared with Hyaluronic Acid Injections for the Treatment of Osteoarthritis of the Knee: AProspective, Randomized Trial. J Bone Surge Am 85: 1197-1203.

7. Adrian C Jones (1995) Intra-articular hyaluronic acid compared to intra-articular triamcinolone hexacetonide in inflammatory knee osteoarthritis. Osteoarterithis and Cartilage 3(4): 269-273.

8. STerryCanale, James H (2013) Beaty, Campbell's Operative Orthopaedics, $12^{\text {th }}$ edn. Philadelphia, Elsevier.

9. Zahedi A, Esmailijah AA, Dehghan M , Okhovatpour MA, Safdari F, et al. (2011) Survey the Effect of Hyaluronic Acid Injection in the Prevention of Hip Osteonecrosis in Dog. Journal of Medical Faculty Guilan University of Medical Sciences 20(78) : 16-20

10. Mehrnoosh Hasas Y, Mohammad Reza A, Ali Akbar E, Hamid Reza $\mathrm{H}_{,}$ Seyed Mohammad J, et al. (2008) Effect of Intra-Articular Hyaluronic Acid or Methyl Prednisolone, or Oral Anti-Inflammatory Drugs in Knee Osteoarthritis: A Comparative Study. Iranian Journal of Orthopedic Surgery 6(22): 74-80.

11. Saied Razavi, Firooz Madadi, Mahshid Nikooseresht, Farshad Hassanzadeh Kiyabi, Seyed Masoud Hashemi, et al. (2017) Intra-articular hyaluronic acid injections Vs. dextrose prolotherapy in the treatment of osteoarthritic knee pain. Tehran University Medical Journal 70(2): 119-125.

12. Raveendhara Bannuru, nikola Natov, Obadan, lori l Price, christopher h Schmid, et al. (2009) Therapeutic Trajectory of Hyaluronic Acid Versus Corticosteroids in the Treatment of Knee Osteoarthritis. 61(12): 1704-1711.

13. Cremer p, Sharif M, GeorgeE, Meadows K, Cushnaghan J, et al. (1994) Intra-articular hyaluronic acid in osteoarthritis of the knee. Osteoarthritis and Cartilage 2: 133-140. 


\section{Your next submission with Juniper Publishers will reach you the below assets}

- Quality Editorial service

- Swift Peer Review

- Reprints availability

- E-prints Service

- Manuscript Podcast for convenient understanding

- Global attainment for your research

- Manuscript accessibility in different formats

( Pdf, E-pub, Full Text, Audio)

- Unceasing customer service

Track the below URL for one-step submission https://juniperpublishers.com/online-submission.php 